\title{
El forraje verde hidropónico (FVH), de maíz como alternativa alimenticia y nutricional para todos los animales de la granja
}

\section{The hydroponic green fodder (FVH), corn as a nutritional and nutritional alternative for all farm animals}

\author{
Chavarría Tórrez, Agustín; Castillo-Castro, Sandra del Socorro; \\ Blanco-Roa, Editor Academico Prof. Dr. Noel Ernesto
}

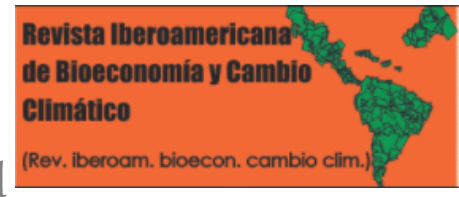

Agustín Chavarría Tórrez

Aguschava98@outlook.es

Universidad Nacional Autónoma de Nicaragua, León.

CUR Jinotega., Nicaragua

Sandra del Socorro Castillo-Castro

Aguschava98@outlook.es

Universidad Nacional Autónoma de Nicaragua, León.

CUR Jinotega, Nicaragua

Editor Academico Prof. Dr. Noel Ernesto Blanco-

Roa

Universidad Nacional Autónoma de Nicaragua, León.

Escuela de ciencias agrarias y veterinarias., Nicaragua

Revista Iberoamericana de Bioeconomía y Cambio Climático

Universidad Nacional Autónoma de Nicaragua, León, Nicaragua ISSN-e: 2410-7980

Periodicidad: Semestral

vol. 4, núm. 8, 2018

czuniga@ev.unanleon.edu.ni

Recepción: 21 Febrero 2018

Aprobación: 15 Noviembre 2018

URL: http://portal.amelica.org/ameli,

jatsRepo/394/3941755005/index.html

DOI: https://doi.org/10.5377/ribcc.v4i8.6716

Autor de correspondencia: Aguschava98@outlook.es
Resumen: Los experimentos ejecutados se basan en la explotación agrícola y de uso pecuario, ya que se aprovecha una cosecha agrícola, para complementar la alimentación animal, usando alternativas poco comunes, tal es el caso del FVH (forraje verde hidropónico) de maíz artesanal, un alimento poco usado por falta de conocimiento en nuestras zonas, pero que a nivel internacional es muy reconocido por su fácil manejo y el gran porcentaje nutricional que este contiene.

Palabras clave: Forraje, Hidropónico, Maíz, Artesanal, Alimento.

Abstract: The experiments carried out are based on agricultural and livestock use, since an agricultural harvest is used to supplement animal feed, using unusual alternatives, such as the HVF (hydroponic green forage) of artisanal corn, a food Little used for lack of knowledge in our areas, but internationally recognized for its easy handling and the high nutritional percentage it contains.

Keywords: Forage, Hydroponic, Corn, Artisan, Food.

\section{INTRODUCCIóN}

El forraje verde hidropónico $(\mathrm{FVH})$ es una metodología de producción de alimento para el ganado que resulta propicia para evadir las principales dificultades encontradas en zonas áridas y semiáridas para la producción convencional de forraje. Las zonas áridas han sido consideradas como terrenos marginales para el desarrollo del sector agropecuario, siendo las razones principales para esta consideración la escasez permanente de

\section{NotAS DE AUTOR}


lluvia, alta evaporación, y suelos y aguas de riego de baja calidad. No obstante, estas limitaciones, la creciente demanda de productos agropecuarios ha ocasionado que tanto la agricultura como la ganadería hayan sido introducidas en ecosistemas frágiles de zonas áridas y semiáridas, los cuales son muy susceptibles a la degradación y en donde es improbable sostener altos rendimientos de manera sostenible para intentar satisfacer las necesidades (Cassman, 1999; Young, 1999). En los últimos años, la actividad agropecuaria en estas zonas se ha incrementado notablemente; sin embargo, su expansión ha tenido lugar sin el debido control ecológico y las tecnologías comúnmente utilizadas no son las más apropiadas, provocando problemas de contaminación de suelos y mantos acuíferos (Endo et al., 2000), agotamiento de agostaderos y la extinción de especies de flora nativa (Martínez-Balboa, 1981).

Un sistema de producción agropecuario sostenible debe mejorar o al menos mantener los recursos naturales sin devaluarlos, y no generar situaciones que disminuyen la actividad ganadera, como por ejemplo la contaminación (Nardone et al., 2004). Consecuentemente, la búsqueda de metodologías alternativas de producción de forraje en las cuales se considere el ahorro de agua, altos rendimientos por $\mathrm{m}^{2}$ ocupado, calidad nutricional, flexibilidad en la transferencia y mínimos impactos negativos sobre el medio ambiente es de particular importancia.

Considerando los puntos anteriores, se puede decir que el FVH puede constituirse en una opción a los métodos convencionales de producción de forraje que contribuya a una actividad agropecuaria sostenible en las zonas áridas y semiáridas.

El FVH es un complemento alimenticio y nutricional que se le puede suministrar en las dietas de todos los animales de la granja, es una tecnología que tiene diversas ventajas para el productor, ya que disminuye los costos de producción, el tiempo de producción de alimento, la compactación de suelo por sobrepastoreo, la contaminación del agua. Junto a ello aumenta la taza de producción y reproducción de los animales, altamente palatable y digestible para los animales en porciones indicadas (AGRICULTURESRS, 2014).

Este tipo de forraje en un $95 \%$ se produce con agricultura de precisión lo cual es un impedimento para que pequeños productores lo cultiven, por esta razón es necesario realizar diseños artesanales para la producción de $\mathrm{FVH}$, así brindamos más alternativas agroecológicas a los productores agropecuarios.

El objetivo es dar el mejor aprovechamiento posible a las semillas cultivadas por los pequeños productores, para darle más valor y utilidad.

Este es uno de los primeros diseños realizados en el país esperando darle respuesta positiva a los productores y que tengamos una buena aceptación por parte de ellos, además que este documento sirva para posteriores investigaciones (FAO, 2001).

\section{REVISIÓN DE LA LITERATURA.}

El forraje verde hidropónico es el resultado del proceso de germinación de granos de cereales o leguminosas (maíz, sorgo, cebada, trigo, alfalfa etc.) sobre charolas. Se realiza durante un periodo de 7 a 14 días, captando la energía del sol y asimilando los minerales de la solución nutritiva.

Hay que recordar que para la producción de Forraje Verde Hidropónico no se utiliza ningún sustrato, solamente semilla forrajera, charola forrajera, una solución nutritiva adecuada para la producción del forraje y agua.

El grano germinado alcanza una altura promedio de 25 centímetros; el animal consume desde la parte aérea formada por el tallo y las hojas verdes hasta los restos de semilla y la raíz. Este procedimiento permite la producción intensiva de forraje fresco para animales de trabajo ó engorda (ya sean vacas, caballos, cerdos, borregos, conejos, cuyos, gallinas, etc.), que maximiza el aprovechamiento de espacio y de recursos, con muy buenos resultados (Hidroenvironment, 2017).

\section{Ventajas y Desventajas del FVH del Maíz}

1. Producción programada de acuerdo con sus necesidades. 
2. Reemplazo de los suplementos alimenticios (piensos compuestos, heno, ensilado, etc.)

3. Alta digestibilidad y calidades nutricionales, excepcionalmente apto para la alimentación animal.

4. Se puede producir en cualquier clima y época del año, con un ahorro significativo de agua, recurso cada vez más limitante y clave en nuestro desarrollo productivo.

5. Aumento de la producción de leche y carne. Al sustituir parte de la ración por FVH produce un aumento en el volumen de leche entre el $12 \%$ y el $20 \%$.

6. Bajos costes de producción.

7. Permite la semiestabulación y la estabulación del ganado.

8. Alta producción en espacios reducidos.

9. Baja mano de obra para su manejo.

10. Muy apetecible por los animales y contiene enzimas digestivas que ayudan a una mejor asimilación del resto de la ración. Tiene un efecto de insalivación por parte del animal que le permite digerir con mayor facilidad el resto del alimento.

11. Bajo en contaminantes para los animales, al estar producido en atmosfera controlada.

12. Alto contenido en proteína y aporta gran cantidad de vitaminas al animal, como, por ejemplo: Vitamina E; Complejo B. A la vez, el FVH es generador de las vitaminas esenciales como la Vitamina A y la Vitamina C, por tener una alta cantidad de carotenos.

13. El FVH provoca un aumento de la fertilidad en los animales. Suministrando este alimento el período de "vientre vacío", pasa de 4-5 meses a poco más de 2 meses. Esto es por el aumento en el consumo de Vitamina E originado por el FVH.

14. Soluciona un problema muy común entre los ganaderos como es a la consecución de proteína y el elevado costo en el mercado de los suplementos alimenticios, que se evita con la producción de FORRAJE VERDE HIDROPÓNICO (Franco, 2016).

\section{Desventajas}

La única desventaja que presenta el FVH es el bajo contenido de fibra, por este motivo se recomienda como suplemento alimenticio y no como dieta completa para alimentar los animales (Franco, 2016).

\section{Elaboración del Forraje Hidropónico.}

Material genético.

Evaluación del rendimiento.

Densidad de siembra

Lavado y desinfección de semillas.

Germinación de semillas.

Siembra en bandejas.

Crecimiento y cosecha (Campabadal, C. 2009).

Calidad Nutricional del FVH. (Tabla Nº 1 )

Tabla $\mathrm{N}^{\circ} 1$

\begin{tabular}{lllll}
\hline Nutriente & Raíces & Tallos & Hojas & Total \\
\% Proteína Cruda & 12.2 & 27.2 & 35.3 & 16.0 \\
\% Grasa & 5.7 & 4.6 & 3.8 & 5.4 \\
\% Fibra Cruda & 10.3 & 26.3 & 21.5 & 12.9 \\
\% E.L.N & 69.3 & 36.8 & 34.7 & 62.6 \\
\% Ceniza & 2.6 & 5.2 & 4.8 & 3.0 \\
\% N.T.D & 84.1 & 61.3 & 76.3 & 80.1 \\
\hline
\end{tabular}

Otras alternativas de producción de FVH 


\section{El Invernadero para FVH}

El invernadero deberá construirse de acuerdo con la cantidad de forraje que se quiera producir diariamente, dejando siempre un margen de seguridad.

Se sabe que en 1 metro cuadrado es suficiente para producir 352 kilogramos aproximadamente de peso húmedo por día de forraje. (Este valor corresponde a la producción en condiciones de humedad y temperatura estables), y sí quieres maximizar tu producción y espacio puedes utilizar racks o anaqueles de 5 niveles.

\section{Construcción del Invernadero.}

El invernadero tendrá características de acuerdo al clima del lugar en que se vaya a establecer la producción de forraje.

Si es para climas cálidos, podrías construir un invernadero alto para poder controlar mejor el calor, con el techo forrado de plástico blanco que tenga una sombra entre el $25 \%$ y $35 \%$; y cubriendo las paredes laterales con malla anti áfidos para permitir la circulación del aire.

En cambio, si el invernadero es para clima frío, con el fin de regular la temperatura especialmente en horas de la noche, podrías construir un invernadero hermético; esto es, un invernadero cuyo techo y paredes estén forrados de un plástico lechoso con sombra entre $25 \%$ y $35 \%$.

El piso.

Éste debe ser de concreto, ya que por la frecuencia de riegos y la alta humedad relativa es el más funcional para evitar encharcamientos, proliferación de hongos y enfermedades.

\section{Estructura de Soporte.}

Puede ser de metal (puedes utilizar perfil sujetador y alambre zig zag para fijar los plásticos o mallas), PVC y madera, aunque no es tan recomendable para sitios húmedos porque puede generar la presencia de hongos.

\section{Modulación.}

Generalmente, para sostener las charolas de forraje, se construyen anaqueles de 4 a 6 niveles, separados entre si por pasillos de 1 metro de ancho, para facilitar las labores de siembra, cosecha y aseo. La altura que debe de existir, entre cada nivel debe ser de cincuenta centímetros y el primer nivel distar del suelo aproximadamente unos $30 \mathrm{~cm}$, cada nivel debe tener una pendiente de $10^{\circ}$ para drenar la solución sobrante de las bandejas (Santander, F, 2006).

\section{El sistema de Riego.}

Hay varios sistemas de riego recomendados para la producción de Forraje Verde Hidropónico: por gravedad, por microaspersión y por nebulización.

$\mathrm{Al}$ sistema de riego nebulizado o micro aspersión se le instala una tubería aproximadamente de $35 \mathrm{a} 40 \mathrm{~cm}$ altura de las charolas forrajeras y se le instalan los nebulizadores o microaspersores; para los sistemas de un nivel será un nebulizador por charola, pero para los sistemas que van en anaqueles hydroenviroment puedes utilizar un nebulizador por dos charolas forrajeras.

Los sistemas de riego por microaspersión y nebulizado son de los que han dado mejores resultados; porque a diferencia de otros sistemas el riego es proporcional, uniforme y el tamaño de la gota no ocasiona ningún daño a la semilla, además que ayuda a incrementar humedad relativa del invernadero (HYDROENVIRONMENT, 2017).

\section{Resultados}

Producción de FVH de maíz artesanal.

1Lb de semilla de maíz = 3 Lb de FVH de maíz. 1qq de semilla de maíz = 300 Lb de FVH de maíz. Listos para el consumo de cualquier especie de explotación pecuaria de la granja integral. 


\section{Conclusiones}

Estas alternativas artesanales de producción de $\mathrm{FVH}$, están dirigidas a los pequeños productores, con el fin de aprovechar dela mejor manera los recursos de sus fincas y de esta manera ahorrar dinero tiempo así como también convertir su granja en auto sostenible.

\section{Literatura Citada}

AGRICULTURESRS. (2014). Orígenes y uso del forraje verde hidropónico. Obtenido de agriculturers.com/ orígenes-y-uso-del- forraje-verde-hidropónico.

FAO, (2001). Forraje verde hidropónico. Manual técnico; mejoramiento de la disponibilidad de alimentos en los Centros de desarrollo infantil del INNFA. Regional de la FAO para América Latina y el Caribe. Santiago de Chile. Obtenido de http://www.fao.org/3/a- ah472s.pdf

Campabadal, Carlos. (2009). Guía Técnica para alimentación de cerdos. Obtenido de http://www.mag.go.cr/ bibliotecavirtual/L02-7847.PDF

Franco, G. P. (2016).Ventajas y desventajas del forraje verde hidropónico. Blogger. Obtenido de http:// fvhaprende.blogspot.com/2016/04/ventajas-y-desventajas-del-fvh.html

Hidroenvironment. (2017).Que es el forraje verde hidropónico? Obtenido de http://hydroenv.com.mx/catalogo/ index.php?main_page=page\&id $=125-127$

Santander, F. (2006). Forraje Verde Hidropónico. El mejor guía. Obtenido de http://www.elmejorguia.com/ hidroponia/Forraje_verde_hidroponico_Ventajas.htm

Kenneth G. Cassman, (1999). Intensificación ecológica de los sistemas de producción de cereales: potencial de rendimiento, calidad del suelo y agricultura de precisión. PINAS.96 (11)

Orán R. Young, (1999) La efectividad de los regímenes ambientales internacionales: conexiones causales y mecanismos de comportamiento. Editorial The MIT Press, ISBN-10 : 0262740230

Madin Kairat; Sawasaki Tatsuya; Ogasawara Tomio; Endo Yaeta (2000).Un sistema de síntesis de proteínas sin células altamente eficiente y robusto preparado a partir de embriones de trigo: las plantas aparentemente contienen un sistema suicida dirigido a los ribosomas. PINAS, 97 (2), pag 559 - 564; https://doi.org/10.1073/pnas.97.2.559

Martínez Balboa, Aurelio (1981), La ganadería en Baja California Sur, vol. 1, editorial La Paz, Baja California Sur

Nardone. A, Zervas. G, Ronchi. B (2004); Sostenibilidad de los sistemas orgánicos de producción de pequeños rumiantes, Ciencia de la producción ganadera. Volumen 90, Número 1, pág 27-39, https://doi.org/10.1016/ j.livprodsci.2004.07.004 